\section{A Case Report of Bloom Syndrome Complicated by Colonic Cancer Due to Polyposis Degeneration: The Importance of Colorectal Cancer Screening}

Chaouch MA*, Nacef K, Ghannouchi M, Khalifa MB, Chaouch A and Boudokhane M

Department of General Surgery, Taher Sfar Hospital, Ksar Hellal, Monastir Government, Mahdia, 28 Gafsa Street, Tunisia

\begin{abstract}
Bloom syndrome is a rare autosomal recessive disorder that attributes a chromosomal instability leading to a high risk of cancer at an early age. We report a case of Bloom syndrome in a 30-year-old man with colonic cancer due to polyposis degeneration. The diagnosis of BS was suspected at the age of five years behind growth retardation, facial sun-sensitive telangiectatic erythema and repeated respiratory infections. The patient underwent a total colectomy. The patient recovered without complication and is currently being followed with endoscopic surveillance of the rectal stump. We present a case report about CRC diagnosed in a Bloom syndrome patient at an early age to suggest the necessity of CRC screening for these patients. Then, we recommend the necessity of doing at least annual examinations and colonoscopy as well as a rapid and thorough investigation of any new symptoms.
\end{abstract}

Keywords: Colonic cancer; Bloom syndrome; Colonic polyposis; Screening

\section{Introduction}

Bloom syndrome (BS) is a rare autosomal recessive disorder that attributes a chromosomal instability, described at the first time in 1954 by David Bloom, a dermatologist [1]. The Bloom's syndrome registry (http://weill.cornell.edu/bsr/) reports 265 patients (140 male and 125 female) worldwide of whom about $26 \%$ are Ashkenazi Jewish ancestry, reaching a frequency of approximately 1 in 48000 [2]. Bloom syndrome is associated with the early occurrence of various cancer [3]. These patients develop the same tumour observed in the general population. However, they occur at an earlier age. Colon cancer is one of the most common tumours reported [4]. We report a case of Bloom syndrome in a 30-year-old man with colonic cancer developed due to polyposis degeneration to suggest the importance of colon and rectal cancer (CRC) screening for these patients.

\section{Case Report}

A 30-year-old, non-Ashkenazi Jewish man, with BS and hypothyroidism operated for ectopic testicular in 2011, developed in July 2013 an abdominal pain relieved by recurrent diarrhoea specially located in the right lumbar and iliac regions, slightly abdominal distension, asthenia, loss of appetite and weight loss. Which occurred intermittently over at least a 3-month-period before he sought medical attention. There was no family history of the genetic disorder, personal or family history of colorectal carcinoma. Manifestations of BS in this patient included a severe growth deficiency even though the proportions of the body are normal with a slightly small cranium, a generalized facial erythema with facial telangiectasia like a butterfly-shape, fissuration in the lower lip and areas of hypopigmentation over the chest and back. He has also a long and narrow face, a high-pitched voice. Semen analysis shows azoospermia. He has a lower concentration of plasma immunoglobulins that cause immunodeficiency. The abdominopelvic CT with lower gastrointestinal opacification objectified an infiltrative process ferrule of the inner face of the cecum infiltrating the ileocecal valve (Figure 1). Colonoscopy revealed numerous polyps located throughout the colon, but predominantly in the cecum and ascending colon, associated with polypoid and ulcerated cecum tumour (Figure 2). Biopsy specimens of the mass showed adenocarcinoma. The patient underwent an uneventful total abdominal colectomy with ileorectal anastomosis. The colectomy specimen revealed 3 polyps. Histologic analysis revealed two tubulovillous adenomas with high-grade dysplasia and adenocarcinoma well differentiated due to attenuated polyposis infiltrating the entire colon wall until the subserosa without exceeding it with lymph node metastasis. The patient has had a complement of chemotherapy that was complicated by orchitis then stooped in the 6th cure of 9 cures. Actually, the patient recovered without complication and is currently being followed with surveillance sigmoidoscopy of the rectal stump.

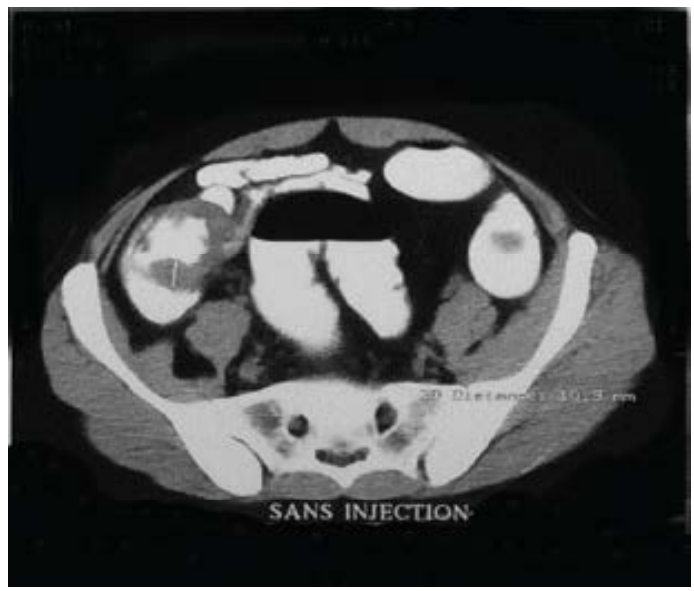

Figure 1: Abdominal CT scan showed an infiltrative process of the inner layer infiltrating the ileocecal valve.

*Corresponding author: Dr. Mohamed Ali Chaouch, Department of General Surgery, Taher Sfar Hospital, Mahdia, Monastir Government, 28 Gafsa Street, Ksar Hellal, Tunisia, Tel: +21626205105; E-mail: Docmedalichaouch@gmail.com

Received December 17, 2018; Accepted December 27, 2018; Published December 31, 2018

Citation: Chaouch MA, Nacef K, Ghannouchi M, Khalifa MB, Chaouch A, et al (2018) A Case Report of Bloom Syndrome Complicated by Colonic Cancer Due to Polyposis Degeneration: The Importance of Colorectal Cancer Screening. J Mol Genet Med 12: 386 doi:10.4172/1747-0862.1000386

Copyright: @2018 Chaouch MA, et al. This is an open-access article distributed under the terms of the Creative Commons Attribution License, which permits unrestricted use, distribution, and reproduction in any medium, provided the original author and source are credited 
Citation: Chaouch MA, Nacef K, Ghannouchi M, Khalifa MB, Chaouch A, et al. (2018) A Case Report of Bloom Syndrome Complicated by Colonic Cancer Due to Polyposis Degeneration: The Importance of Colorectal Cancer Screening. J Mol Genet Med 12: 386 doi:10.4172/17470862.1000386

Page 2 of 2

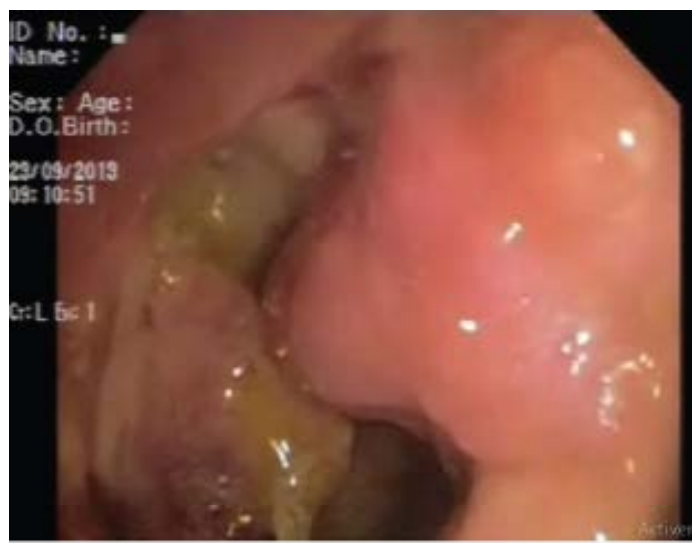

Figure 2: Colonoscopic view of the polypoïd and ulcerated cecum tumour.

\section{Discussion}

We present this clinical case on the diagnosis of CRC in a patient with Bloom syndrome at an early age to suggest the importance of CRC screening in this population. Bloom syndrome belongs to a group of "chromosomal breakage syndromes" which are transmitted in an autosomal recessive mode. The commonly acknowledged chromosomal breakage syndrome are fanconi anaemia, ataxia telangiectasia, xeroderma pigmentosum and Bloom syndrome. However, genetically confirmation is necessary to eliminate a differential diagnosis. Growth deficiency is frequently the first manifestation that causes parents to seek medical attention. Patients with Bloom syndrome have a photosensitive lupus-like rash on the face, areas of café-au-lait spots [5]. The decrease of immunoglobulin level leads to recurrent respiratory and gastrointestinal tract infections [6]. A cytogenetic analysis looking for increased sister chromatid exchanges can then confirm or refute the diagnosis. Making the diagnosis has important management implications due to the increased risk of malignancy, probable hypersensitivity to chemotherapy and radiotherapy, and also the possibility that patients with Bloom syndrome are more likely to suffer from a range of complications of all treatments due to the other features of the condition immunodeficiency [7]. Then we should take extreme caution in using chemotherapy in patients with this disorder. Several authors reported similar toxicities in patients affected by Bloom syndrome associated with cancers (epipharyngeal B-celltype lymphoma, nasopharyngeal B-cell-type malignant lymphoma, Burkitt lymphoma, hepatocellular carcinoma, Wilms tumour) $[8,9]$. As in the normal population, the colon is a common site of malignancy in persons with BS. The incidence of colonic adenomas among BS patients is unknown. The increased risk of malignancy in patients with colonic adenomas and BS is well established. Among the 210 individuals followed in The Bloom's Syndrome Registry, there are now documented 16 cases of colorectal malignancy (James German, personal communication, January 2001). Of the 16 cases,
12 males and 4 females. The median age of affected persons was 33.2 years, (range, 16-44) which is significantly lower than the mean age of the general population. Of the 16 lesions, 6 arose in the right side of the colon, 3 in the transverse colon, and 5 arose in the left colon or rectum [10]. Colorectal tumours in BS and normal individuals have generally similar distribution. But the individuals with BS seems to have more right-sided and transverse colon tumours [10]. To make a definitive conclusion is impossible due to the small number of cases. The treatment of carcinomas by surgical resection at an early stage is the best curative option for the adult patient. Then, we recommend the necessity of CRC screening in this population by doing at least annual examinations as well as rapid and thorough investigation of any new symptoms.

\section{Conclusion}

The genetic disorder responsible for BS is uncovered. Genetic testing is currently available for diagnostics and to identify asymptomatic persons. BS is a worldwide, even in Tunisia, a rare genetic disorder. Only two cases are registered in Bloom syndrome register from North Africa. It might be more common. This population is exposed to develop cancer at a young age, particularly breast and colon carcinomas. Then a screening program should be offered to diagnose and treat these two cancers at an early stage avoid severe side effects. The possibility of antenatal diagnosis is possible when the risk of BS transmission is well evaluated.

\section{Author Disclosures}

Authors have no conflicts of interest or financial ties to disclose.

\section{References}

1. Amor-Gueret M (2006) Bloom syndrome, genomic instability and cancer: The SOS-like hypothesis. Cancer Lett 236: 1-12.

2. Shahrabani-Gargir L (1998) High frequency of a common Bloom syndrome Ashkenazi mutation among Jews of Polish origin. Genet Test 2: 293-296.

3. Hickson ID, Rec Q (2003) Helicases: Caretakers of the genome. Nat Rev Cancer 3: 169-178.

4. Bruno W, Fornarini G, Ghiorzo P (2015) Signs and genetics of rare cancer syndromes with gastroenterological features. World J Gastroenterol 21: 8985-8993.

5. Monnat RJ (2010) Human RECQ helicases: Roles in DNA metabolism mutagenesis and cancer biology. Semin Cancer Biol 20: 329-339.

6. Bloom D (1954) Congenital telangiectatic erythema resembling lupus erythematosus in dwarfs; probably a syndrome entity. AMA Am J Dis Child 88: 754-758.

7. Thomas ER (2008) Surveillance and treatment of malignancy in Bloom syndrome. Clin Oncol 20: 375-379.

8. Fedhila-Ben Ayed F (2016) Burkitt lymphoma in a child with Bloom syndrome. Arch Pediatr 23: 382-384.

9. Berger C (1996) Wilms tumor and Bloom syndrome. Arch Pediatr 3: 802-805.

10. Lowy AM (2001) Numerous colonic adenomas in an individual with Bloom's syndrome. Gastroenterol 121: 435-439. 